\title{
Parametric Optimization and Control of Heat Exchanger using Linear Quadratic Controller and Dynamic Matrix Controller
}

\author{
E. Kesavan ${ }^{1}$, N. Divya ${ }^{2}$, N. Gowthaman ${ }^{3}$, S. Manoharan ${ }^{4}$ \\ ${ }^{1}$ Assistant Professor, RMK Engineering College, RSM Nagar, Chennai, Tamilnadu, India \\ ${ }^{2,3}$ Assistant Professor, ${ }^{4}$ Professor, Karpagam College of Engineering, Coimbatore, Tamilnadu, India
}

\begin{abstract}
Heat exchanger plays a important role in many unitsas they have the capability to hold different temperarure and pressure range. In this paper the linear quadratic controller and Dynamic matrix controller is implemented for heat exchanger system. The out let temperature of the tube is controlled by monitoring the inlet flow rate by using different controllers. The model of the system has been obtained from experimental data using system identification technique. The LQR and DMC is compared by analyze the servo performance in the system in terms of settling time, overshoot and rise time.
\end{abstract}

Keywords: Heat exchanger system, DMC controller, LQR Controller, Cold water temperature

\section{Introduction}

The proposed plants are commonly used in many industries like gas industries, nuclear power plants, petrochemical industries[1]. Heat exchangers are used to conduct the heat between two difference temperature medium like liquids and gases. The additional advantages of proposed system are low cost and high efficiency [2]. The heat exchanger has variable time constant and steady state gain for different flow rate in the tube of heat exchanger.[3]. The conventional controllers provide poor servo and regulatory performance for different operating region [4][5]. Here the controlled variable and manipulated variables are cold water outlet temperature of cold water and inlet temperature of cold water. Controlling and modeling of our system is very difficult due to the non linearity presence in the heat exchanger.[6],[7],[8]. Among the various types of heat exchanger shell and tube heat exchanger provides more efficiency than other.[9][10]. Various approaches to obtaining mathematical of heat exchanger system is developed by various authors [11][12][13]. The dynamic and static behaviors of the controller are analyzed by performing real time experimentation on heat exchanger. The proposed Dynamic matrix controller provides best servo and regulatory performance than other controller

\section{Heat Exchanger System}

There are many tubes placed inside of the shell in the heat exchanger. Here the heat is transferred from shell side to tube side. The water flowing through the tube is not having direct contact with the shell, but the transfer of heat takes place in the heat exchanger. Heat transfer rate is analyzed by adjusting the incoming flow rate to tube. The aim of this work is to control temperature of tube outlet. In order to design the linear quadratic regulator the model of the heat exchanger system needs to be derived. The model of the given system is identified by on line estimation of process parameters.

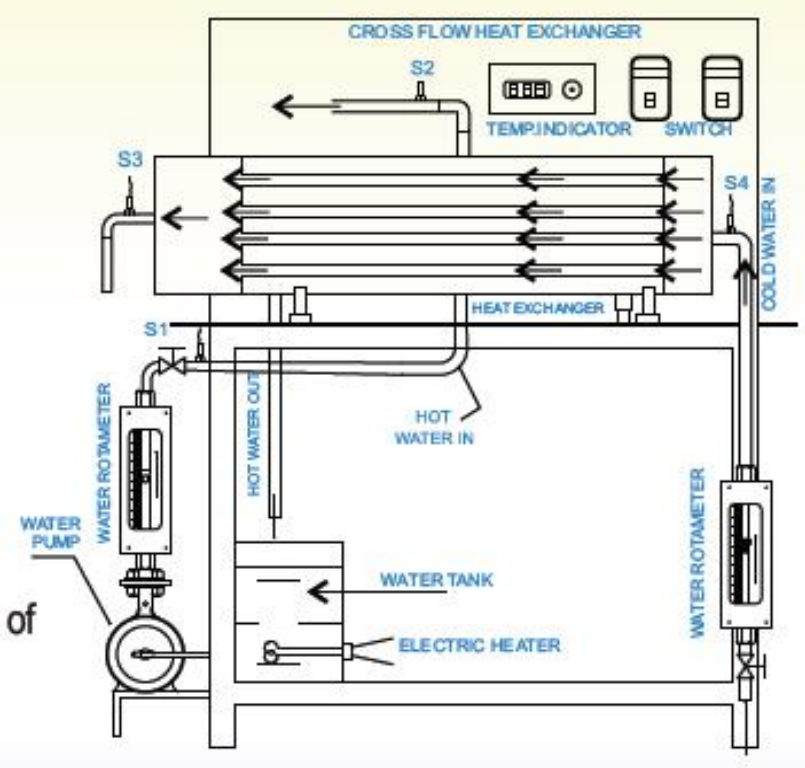

Fig.1:Heat exchanger setup

Table 1:Shell flow rate and duration

\begin{tabular}{cc}
\multicolumn{2}{c}{ Table 1:Shell flow rate and duration } \\
\hline $\begin{array}{c}\text { Shell inlet flow } \\
\text { rate(LPH) }\end{array}$ & Sampling Instant \\
\hline 350 & 1800 \\
$350-250$ & $1800-3600$ \\
$250-150$ & $3600-5600$ \\
\hline
\end{tabular}




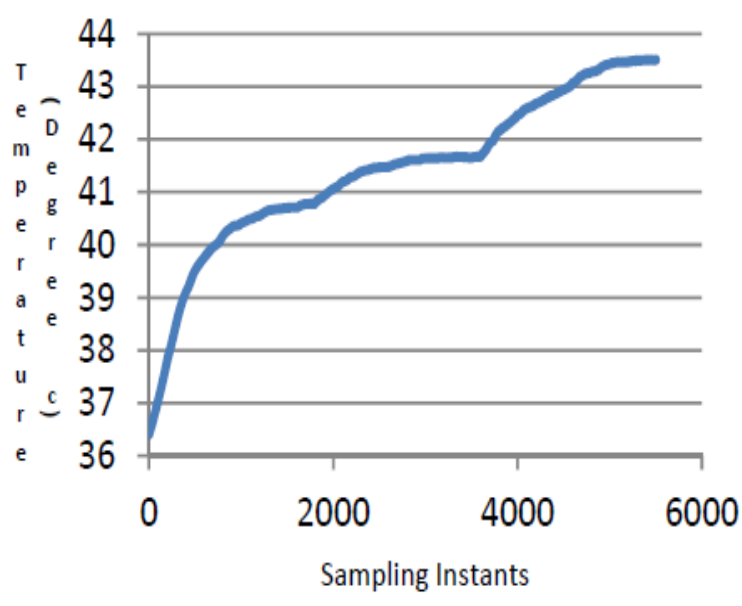

Fig.2:Open loop response of for different flow rate

The system identification technique is used derive the state space model from the experimental input and output data.

$$
\begin{aligned}
& A=\left[\begin{array}{cc}
-0.00019 & 0.00053 \\
0.00063 & 0.00267
\end{array}\right] \\
& B=[1.487 \mathrm{e}-07-1.0238 \mathrm{e}-06]^{\mathrm{T}} \\
& C=[411.910 .12]
\end{aligned}
$$

\section{LQR Controller}

The LQr Controller is very powerful for complex system that have highly nonlinear dynamics. [15] . The cost function is established by the matrices $\mathrm{R}$ and $\mathrm{Q}$, that weight system input and state vector respectively. In the LQR method, the optimal control input is obtained by algebraic Riccatti equation. The linear model of the heat exchanger and linear quadratic control is used to design the state feedback controller.

$$
\dot{\mathrm{X}}(\mathrm{t})=\mathrm{Ax}(\mathrm{t})+\mathrm{Bu}(\mathrm{t}) \quad \mathrm{t} \geq 0 \quad \mathrm{x}(0)=x_{0}
$$

Where $\mathrm{u}(\mathrm{t})$ - input vector and $\mathrm{x}(\mathrm{t})$ - state vector. The matrix $\mathrm{K}$ is determined by the state - feedback control law

$\mathrm{U}(\mathrm{t})=-\mathrm{kx}(\mathrm{t})$

It satisfies the two criteria's are the system is asymptotically stable for closed loop, the quadratic performance functional and cost function

$J(K)=\left(\frac{1}{2}\right) \int_{0}^{\infty}\left[x^{T}(t) Q x(t)+u^{T}(t) R u(t)\right] d t$

The $\mathrm{Q}$ is a non negative matrix that reprimand the system state and the definite matrix is $\mathrm{R}$ that regulate control input[14].The following Linear quadratic regulator design steps used to identify the optimal feedback controller.

Step no1- Solve the matrix Algebraic Reccati Equation

PA-A ${ }^{\mathrm{T}} \mathrm{P}-\mathrm{Q}-+\mathrm{PBR}^{-1} \mathrm{~B}^{\mathrm{T}} \mathrm{P}=0$

Step no2- To find the optimal state ie., $\mathrm{X}^{*}(\mathrm{t})$ using following equation

$X^{*}(t)=\left[A-B R^{-1} B^{T} P\right] X^{*}(t)$

Step no3- Determine the optimal control $\mathrm{u}^{*}(\mathrm{t})$ using following equation

$$
J^{*}=(1 / 2) X^{* T}(t) P X(t)
$$

Step no4- Determine the system performance index from
$J^{*}=(1 / 2) X^{* T}(t) P X(t)$

The weighting matrix $\mathrm{R}$ and $\mathrm{Q}$ are plays important role in linear quadratic controller optimization process. The system performance is based on the composition of matrix $\mathrm{R}$ and $\mathrm{Q}$. Selecting the matrix $\mathrm{Q}$ and $\mathrm{R}$ is depends on dynamic and static characteristics of the given system

\section{DMC Controller}

Several researchers highlighted the features of DMC controller[15],[16]. The features of DMC has been summarized for readers convenience. The DMC controller has adjective function with $\mathrm{V}$ measured process variable and $\mathrm{S}$ controller output.[17]

$\min _{\Delta \overline{\mathrm{u}}} J=[\overline{\mathrm{e}}-A \Delta \overline{\mathrm{u}}]^{T}[\overline{\mathrm{e}}-A \overline{\mathrm{u}}]+[\Delta \overline{\mathrm{u}}]^{T} \Lambda^{T} \Lambda[\Delta \overline{\mathrm{u}}]$

The step response is represented as

$y(t)=\sum_{i=1}^{\infty} g_{i} \Delta u(t-i)$

The predicted value of output can be expressed as

$\hat{y}\left(t+\frac{k}{t}\right)=\sum_{i=1}^{\infty} g_{i} \Delta u(t+k-i)+\hat{n}\left(t+\frac{k}{t}\right)$

$=\sum_{i=1}^{k} g_{i} \Delta u(t+k-i)+\sum_{i=k+1}^{\infty} g_{i} \Delta u(t+k-i)+\hat{n}\left(t+\frac{k}{t}\right)$

The ouput value with disturbance can be written as

$\hat{y}\left(t+\frac{k}{t}\right)=\sum_{i=1}^{k} g_{i} \Delta u(t+k-i)+\sum_{i=k+1}^{\infty} g_{i} \Delta u(t+k-i)+y_{m}(t)$

$-\sum_{i=1}^{\infty} g_{i} \Delta u(t-i)=\sum_{i=1}^{k} g_{i} \Delta u(t+k-i)+f(t+k)$

The response of the system is not depend on the future control is represented by

$X f(t+k)=y_{m}(t)+\sum_{i=1}^{\infty}\left(g_{k+i}-g_{i}\right) \Delta u(t-i)$

$\hat{y}\left(t+\frac{1}{t}\right)=g 1 \Delta u(t)+f(t+1)$

$\hat{y}\left(t+\frac{2}{t}\right)=g 2 \Delta u(t)+g 1 \Delta u(t+1)+f(t+2)$

$\hat{y}\left(t+\frac{p}{t}\right)=\sum_{i=1}^{m} g_{i} \Delta u(t+p-i)+f(t+p)$

$\hat{y}_{v, \min } \leq \hat{y}_{v} \leq \hat{y}_{v, \max }$

$\Delta \overline{\mathrm{u}}_{s, \min } \leq \Delta \overline{\mathrm{u}}_{s} \leq \Delta \overline{\mathrm{u}}_{s, \max }$

$\overline{\mathrm{u}}_{s, \min } \leq \overline{\mathrm{u}}_{s} \leq \overline{\mathrm{u}}_{s, \max }$

A closed form solution for equation (eq .9) can be written as equation (eq. 10).

$\Delta \overline{\mathrm{u}}=\left(A^{T} \Gamma^{T} \Gamma A+\Lambda^{T} \Lambda\right)^{-1} A^{T} \Gamma^{T} \Gamma \overline{\mathrm{e}}$

Here the Dynamic matrix A contains coefficient of output response and controller output for various step input; the vector e is the error signal for $\mathrm{R}$ measured variable over the prediction horizon $\mathrm{P}$; the vector $\mathrm{u}$ is the controller output determined for various sampling instant $\mathrm{M}$ ( Control horizon); $\hat{y}$ is estimated 
process output for the sampling instant P. $\Lambda^{T} \Lambda$ is the diagnal matrix having dimension $(\mathrm{M} * \mathrm{M})$.

\section{DMC Implementation for Heat Exchanger}

DMC controller parameter is determined by using tuning rules given by Cooper and Shridhar[20]. The actual data from process used to design typical DMC controller. The dynamic matrix determined using coefficient of step response. The element $A_{11}$ is formated from the coefficient of process variable for particular shell outlet valve position. The element of $A_{12}, A_{21}, A_{22}$ is constructed for different shell outlet valve position of heat exchanger.

$$
\begin{gathered}
A=\left[\begin{array}{ll}
A_{11} & A_{12} \\
A_{21} & A_{22}
\end{array}\right]_{2 P \times 2 M} \\
A_{i j}=\left[\begin{array}{ccccc}
a_{i j} & 0 & 0 & \ldots & 0 \\
a_{i j, 2} & a_{i j, 1} & 0 & \ldots & 0 \\
a_{i j, 3} & a_{i j, 2} & a_{i j, 1} & \ldots & 0 \\
\ldots & \ldots & \ldots & \ldots & \ldots \\
a_{i j, M} & a_{i j, M-1} & a_{i j, M-2} & \ldots & a_{i j, 1} \\
\ldots & \ldots & \ldots & \ldots & \ldots \\
a_{i j, P} & a_{i j, P-1} & a_{i j, P-2} & \ldots & a_{i j, P-M+1}
\end{array}\right]_{P \times M}
\end{gathered}
$$

The below matrix consist of control variable over the control horizon is formed by using equation (8) and equation (9).

\section{Result and Discussion}

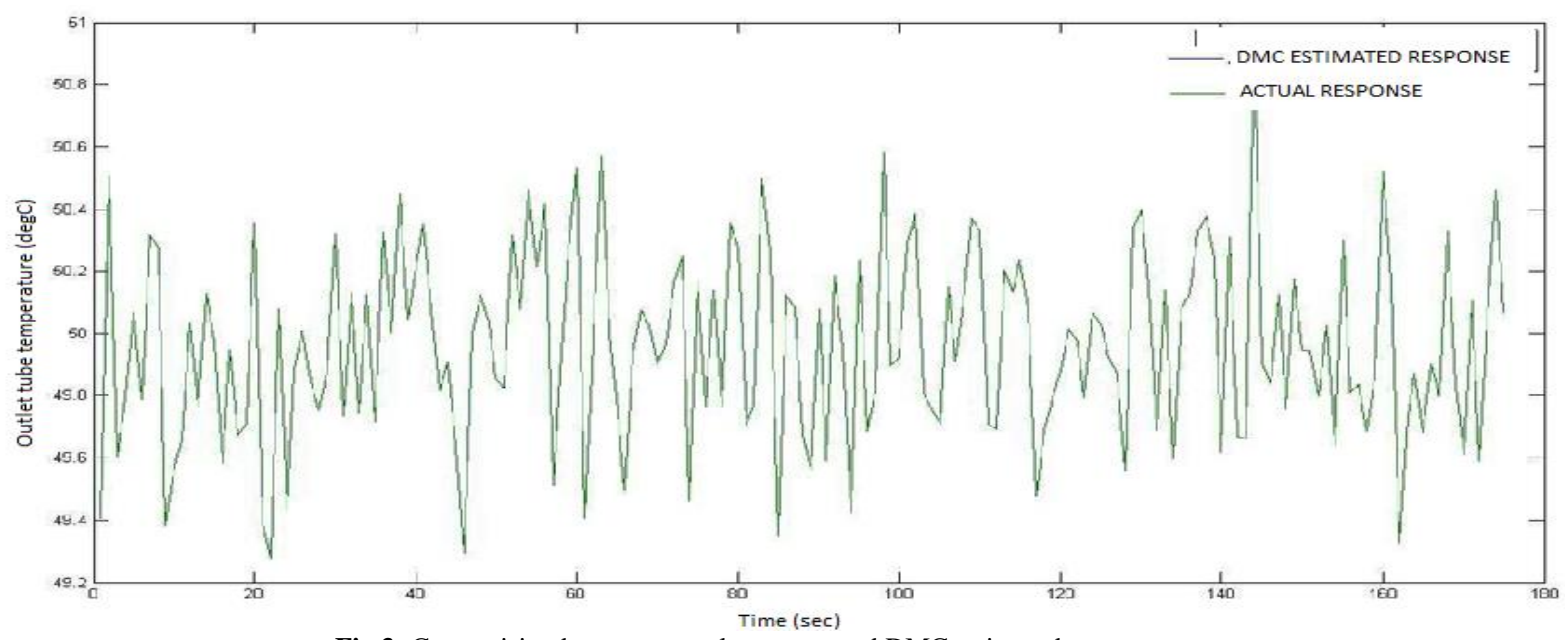

Fig.3: Comparision between actual response and DMC estimated output response

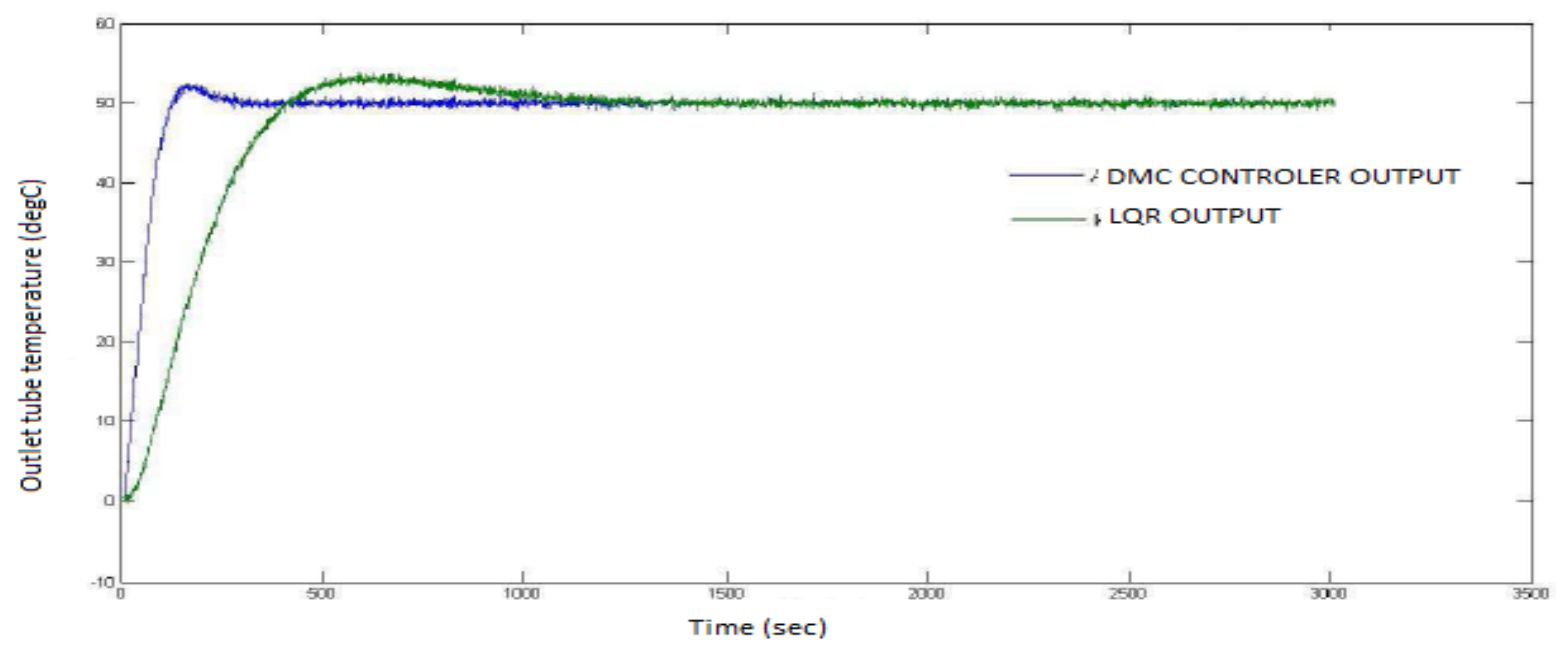

Fig.4: Comparision between LQR response and DMC response 
Table 2: Performance analysis

\begin{tabular}{cccc}
\hline Controller & Rise Time & Over & Settling \\
& $($ SEC $)$ & Shoot $(\%)$ & Time $($ SEC) \\
DMC & 127 & 5 & 340 \\
LQR & 340 & 7 & 1340 \\
\hline
\end{tabular}

The LQR controller and DMC controller are designed and simulated using MATLAB software. Here is the slight difference between output response of LQR controller and DMC controller. The fig. 3 shows the effectiveness of dynamics matrix controller, linear quadratic regulator. The DMC controller provides accurate controller output to achieve desired set point tracking. The change in controller output in DMC controller is based on estimated values of output response of the heat exchanger unit, it ensures perfect control action on servo and regulatory performance.

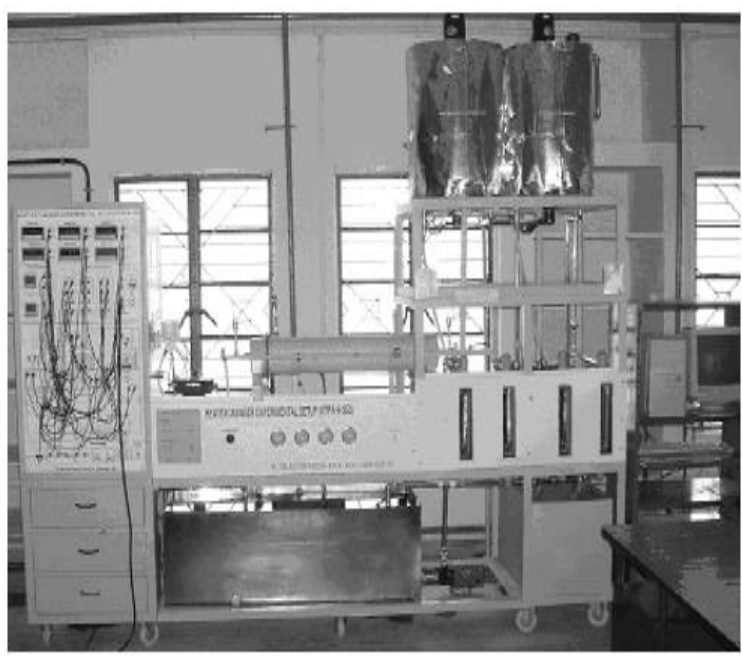

Fig .5: Experimental setup

\section{Conclusion}

In this work, a control scheme based on LQR controller and DMC controller has been implemented for system with heat exchanger. The output response parameters are rise time, settling time and overshoot plays vital role on controller performance analysis. The dynamic matrix controller provides perfect control action in servo performance analysis. The result ensures that, the dynamic matrix controller is the best controller for high time constant and non linear process. The controller scheme is not only good in dynamic process, but also provides robustness for highly disturbances to the process.

\section{Reference}

[1] Alagesan.V, Sundaram.S, "Effect of Heat Transfer Studies on A Water-Palm Oil Two-Phase System in Shell and Tube Heat Exchanger" International journal of ChemTech Research, vol 4(2) PP 502-510. 2012.

[2] Ohadi M.M, N. N.Sharaf and D.A.Nelson. "Electro Hydrodynamic Enhancement of Heat Transfer in a Shell-And Tube Heat Exchanger", Experimental Heat Transfer, Vol.4,19-39, 1991.

[3] M.Chidambaram and Y.S.N. Malleswara rao, "Nonlinear Controllers for heat exchangers", J. Process Control, 2(1), 1721, 1992.

[4] Kesavan, E., and Rakesh kumar, S., PLC based adaptive PID control of NON linear liquid tank system using online estimation of linear parameters by difference equations, International journal of engineering and technology, 5(2), 910-916,2013.

[5] Kesavan.E, Agalya.A, Palpandian.P and Manoharan.S Performance Analysis and Comparison of Different Tuning Strategies of PI Controller in Conical Tank, Indian Journal of Science and Technology, Vol 9(11). 2016,

[6] Manimaran.M, Chitra.V.S, Mohamed rafiq.M,"Block-box modelling and control a temperature of the shell and tube heatexchanger using dynamic matrix controller", Chemtech research, 2015, vol8, no4, pp.1742-1748.

[7] Chitra.V.S, manimaran.M, Petchithai.V, "Nonlinear block-box modelling and control a shell and tube heat exchanger using generalized predictive controller", Chemtech research, 2015, vol.7, no4, pp.1843-1848

[8] Skogested.S, "Tuning for smooth PID controller with acceptable disturbance rejection", Industrial and engineering chemistry reach, 2006, vol.45, no.23, pp.7817-7822.

[9] Garcia.C.E, morshedi.A.M, Quadratic programming solution of dynamic matrix control, Chemical engineering communication, vo $36, p p(73-87)$.

[10] Subhransu Padhee, " Controller design for temperature control of heat exchanger system: simulation studies", WSEAS Transaction on system and control, Volume 9, pp. 485-491, 2014.

[11] Sapna Gupta, Rajeev Gupta, robust tuning oh heat exchanger system using swarm optimization method, International journal of recent technology and Engineering, volume3, issue1, march 2014.

[12] Arun Sivaram, M.Sainabha, K.Ramkumar, parameter identification and control of a shell and tube heat exchanger, International Journal of Engineering and Technology, vol.5(2),pp(1589-1593),2013.

[13] Vinodh Kumar E, Jovitha Jerome, Robust lqr controller design for stabilizing and trajectory tracking of inverted pendulum, International conference on design and manufacturing, icondm, vol.64, pp(169-178), 2013

[14] Cutler.C.R, Rmkumar.D.L, Dynamics matrix control-a computer control algorithm, Proceeding of the JACC, 1980.

[15] [16] Marchetti.J.L, Mellichamp.D.L, Seborg.D.E, Predictive control based on discrete control methods, industrial engineering chemistry, Process design and development, vol 22, pp.488495,1983

[16] Garcia.C.E, morshedi.A.M, Quadratic programming solution of dynamic matrix control, Chemical engineering communication, vo $36, p p(73-87)$ 